\title{
CRISIS Y EMPLEO EN LAS CIUDADES DE ANDALUCÍA ${ }^{1}$
}

\author{
Gema González-Romero \\ Inmaculada Caravaca \\ Departamento de Geografía Humana. Universidad de Sevilla \\ gemagonzalez@us.es ; caravaca@us.es
}

\section{RESUMEN}

El objetivo de este artículo es analizar la evolución experimentada por el empleo en las ciudades andaluzas entre los años 2000-2006, periodo que antecede a la crisis, 2006 y 2009, fase en la que se inicia, y 2009-2012, cuando empiezan a detectarse los efectos de las políticas de austeridad. Se intenta, así, identificar cuáles son los factores que ayudan a entender dicha evolución, considerar las diferentes formas en que los municipios urbanos están siendo afectados por la crisis, y reflexionar acerca de si ésta pudiera estar reafirmando el rol ejercido por las agro-ciudades en el sistema urbano regional. Se utiliza como fuente el Registro de Afiliaciones a la Seguridad Social.

Palabras clave: Crisis, empleo, impactos territoriales, ciudades, Andalucía.

\begin{abstract}
The aim of this paper is to analyze the evolution experienced by employment in the Andalusian towns and cities between 2000-2006, the period preceding the crisis, 2006 and 2009, phasewhereitstarts, and 2009- 2012, when the effects of the austerity policies beginto be detected... Attention will focus on considering the different ways in which the urban municipalities are affected by the crisis, and reflecting on whether it might be reaffirming the role played by the agricultural towns in the regional urban system. The fundamental source used for analysing employment is the number of employed people registered with the Department of Social Security.
\end{abstract}

Keywords: Crisis, employment, territorial impacts, cities, Andalusia.

Fecha de recepción: diciembre 2014.

Fecha de aceptación: junio 2015.

1 Este artículo se integra en el proyecto de investigación del Plan Nacional de I+D+i: CSO 2012-36170 


\section{INTRODUCCIÓN}

A finales de la primera década del siglo XXI se evidenció la existencia de una profunda crisis que está contribuyendo a poner de manifiesto toda una serie de contradicciones asociadas tanto a la forma en que se ha producido el proceso de globalización, como a los fundamentos que han sustentado el modelo de crecimiento económico neocapitalista.

En su origen intervinieron una serie de causas interrelacionadas que en buena parte se fueron gestando durante las últimas décadas del siglo XX. Destaca entre ellas el proceso de desregulación financiera que contribuyó decisivamente a provocar un fuerte crecimiento de dicho sector económico hasta alcanzar cotas antes desconocidas. Se producía así un creciente predominio de las actividades financieras, en buena parte asociadas a movimientos especulativos, sobre las productivas, que son las que sustentan la economía real, que ha dado lugar a una financiarización de la economía, asociada a una progresiva movilidad del capital tanto entre los mercados financieros como entre firmas, sectores y territorios (Orhangazi, 2008; Corpataux, Crevoisier y Theurillat, 2009). A su vez, la utilización de productos financieros muy sofisticados, opacos y arriesgados ha resultado determinante para que se haya entrado «en una era de riesgos financieros sin precedentes» (Harvey, 2008: 218).

En estrecha relación con lo anterior, se producía un desmedido crecimiento del sector inmobiliario, que contribuyó decisivamente a potenciar la crisis financiera, convirtiéndose en corresponsable de sus impactos no sólo socioeconómicos sino también territoriales. Se ponía en evidencia, una vez más, que el sector de la construcción «por su habitualmente alta participación en el producto y en el empleo, y por su rol estratégico de articulación entre el sector financiero y la economía real, es un factor determinante y detonante de los ciclos de auge y recesión y de las crisis económicas» (Daher, 2013: 48).

Pero la gravedad y la complejidad de la crisis financiero-inmobiliaria han ido en aumento hasta el punto de convertirla en sistémica, llegando a afectar a la economía en su conjunto, al mercado laboral, a las instituciones, a las políticas e incluso a los valores morales y éticos. Se trata, además, de una crisis global, ya que incide en todo el planeta, aunque no es una crisis uniforme, dado que afecta a los territorios con diferentes formas e intensidades.

En este contexto, el caso de España resulta paradigmático, porque en este país entre los impactos generados por la crisis destacan con mucho, además de los financieros e inmobiliarios, los relacionados con el comportamiento del mercado de trabajo. En efecto, mientras que en 2014 la tasa de empleo de la Unión Europea es del 69,2\%, alcanza en España el 59,9\%, superando únicamente a Grecia y a Croacia. La cifra es aún más alarmante si el parámetro analizado es la tasa de paro, pues con el 24,5\%, únicamente se sitúa por debajo de Grecia, encontrándose muy alejada de la media europea (10,2\%) (Eusrostat, 2015). Si, por una parte, resulta llamativo el elevado número de empleos que se han venido destruyendo desde el año 2007 (algo más de 3,2 millones, según la Encuesta Población Activa), por otra, destaca así mismo la creciente precariedad de los puestos de trabajo que desde entonces se vienen generando (Álvarez-Luengo-Uxó, 2013).

El dinamismo económico que había experimentado España desde la segunda mitad de la década de los noventa del pasado siglo estuvo básicamente sustentado por actividades financiero-especulativas y por sectores económicos caracterizados por la utilización de recursos genéricos, como el trabajo de baja cualificación y el uso intensivo de recursos naturales. Entre tales 
sectores destacaba el de la construcción que, aunque contribuyó en gran medida al crecimiento de la economía, provocó otros efectos no deseados entre los que cabe destacar la creación de empleo inestable y precario, y el uso extensivo del suelo, con todos los impactos socio-laborales, territoriales y ambientales que ello conlleva. No puede extrañar, por consiguiente, que al estallar la burbuja financiero-inmobiliaria se pusiera en evidencia la inoperancia de un modelo económico que, a más de ser socialmente injusto, y ambiental y territorialmente agresivo, ni siquiera resultaba ya competitivo (García Bellido, 2005; Fernández Durán, 2006; Naredo, 2010).

No ha de dejarse al margen, además, que las políticas de ajuste que se están implementando, apoyadas por la Unión Europea y otros organismos internacionales como el Fondo Monetario Internacional y el Banco Mundial, no sólo no están contribuyendo a resolver los importantes problemas económicos y socio-laborales que la crisis ha generado sino que, por el contrario, están agravándolos hasta el punto de originar una segunda crisis. Hay que partir de la base de que, dichas políticas tienen como objetivo principal la reducción del déficit en la balanza de pagos; se centran para ello en minimizar el gasto público -en infraestructuras, servicios (algunos básicos como educación y sanidad) y ayudas sociales- sin tener en cuenta que el problema fundamental no está relacionado con los gastos sino con los ingresos, y que la recaudación fiscal favorece sistemáticamente a las grandes fortunas mientras las medidas de control al fraude no resultan operativas (Ayala-Martínez-Ruiz Huerta, 2013; Romero-Collado-Rodríguez, 2014).

Se trata, pues, de políticas que no están respetando los principios básicos de igualdad de oportunidades, sino que, por el contrario, benefician a aquellos grupos sociales cuyos niveles de renta son más elevados; se está favoreciendo así el crecimiento de las desigualdades, con la consiguiente pérdida de cohesión social. Como señala Oxfam Intermón al respecto, las medidas adoptadas para hacer frente a la crisis han contribuido a concentrar el poder económico, propiciando el crecimiento de «una riqueza ilícita que perpetua la desigualdad, supone una amenaza para un modelo social basado en la inclusión e igualdad de oportunidades, y pone en peligro los sistemas democráticos» (Oxfam Intermón, 2014: 1).

En este contexto general de referencia, el objetivo de este artículo es analizar la evolución experimentada por el empleo en los municipios urbanos andaluces ${ }^{2}$ durante el período previo a la crisis y una vez iniciada ésta. Se intenta, así, identificar cuáles son los factores que ayudan a entender dicha evolución, considerar las diferentes formas en que las ciudades ${ }^{3}$ están siendo afectadas por la crisis, y reflexionar acerca de si ésta pudiera estar reafirmando el rol ejercido por las denominadas agro-ciudades en el sistema urbano regional. Se trata, pues, de objetivos de interés por varias razones. Por una parte, porque el empleo es un indicador especialmente ilustrativo de los impactos socioeconómicos generados por la crisis. Por otra, porque las ciudades son espacios estratégicos en los que se concentran la población y las actividades económicas, lo que permite observar con más nitidez los diferentes efectos locales de la crisis y, en consecuencia, diseñar estrategias concretas con las que hacerle frente. Por último, porque el elevado número de ciudades con que cuenta Andalucía y su equilibrada distribución jerárquica y espacial, incrementa el interés por lo que ocurre en estos ámbitos ya que ayuda a profundizar en el conocimiento de los impactos territoriales de la crisis. El esquema de la figura 1 pretende sintetizar este planteamiento.

\footnotetext{
2 Se clasifican como urbanos los municipios que cuentan con 10.000 o más habitantes.

3 Dado el grado de desagregación de la información estadística, para el análisis de las ciudades se toma como referencia el municipio.
} 
Para analizar el empleo se utiliza como variable el número de afiliaciones a la Seguridad Social y como fechas de referencia los años 2000, 2006, 2009 y 2012 (último para el que existe información disponible); con ello se puede observar su evolución en el período que antecede a la crisis, y diferenciar después dos etapas: una primera relacionada con la crisis financiero inmobiliaria y una segunda marcada por las llamadas políticas de austeridad. La mayor parte de los datos proceden del Registro de la Tesorería General de la Seguridad, que se convierte así en fuente estadística básica para la elaboración de este trabajo; no obstante, se utilizan también otras fuentes complementarias como el Padrón Municipal de Habitantes, la Contabilidad Regional de España y la Encuesta de Población Activa.

Figura 1

PLANTEAMIENTO DEL ARTÍCULO

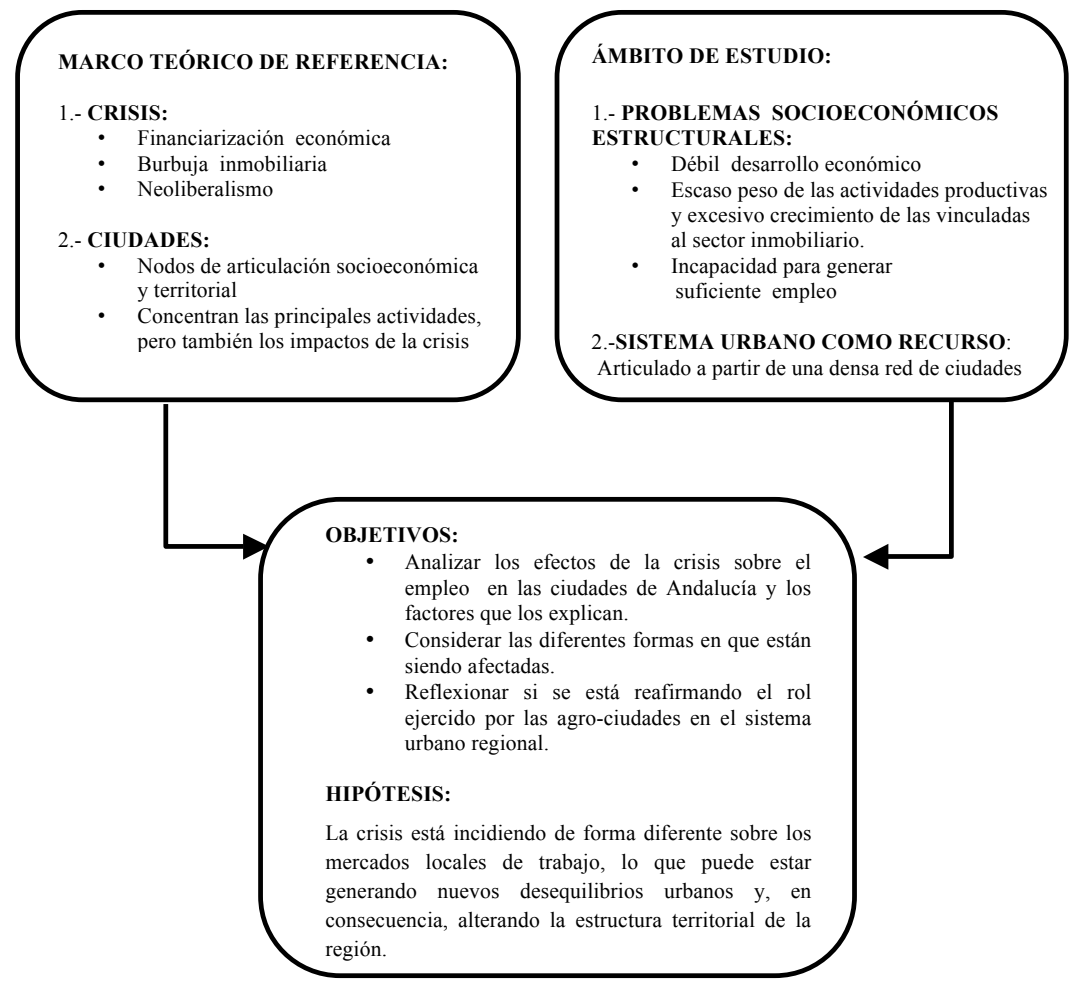

Fuente: elaboración propia.

El artículo se estructura en seis apartados. Tras esta introducción se dedica un epígrafe a contextualizar los efectos de la crisis en Andalucía poniéndolos en relación con lo ocurrido en las otras Comunidades Autónomas. En el tercer apartado se consideran los cambios producidos en el empleo según el volumen de población de los municipios objeto de estudio, lo que permite observar si se están produciendo alteraciones en la estructura del sistema urbano regional. El epígrafe cuarto, por su parte, se centra en el estudio de los cambios territoriales 
ocurridos en el número de afiliaciones considerando para ello las tres fases antes mencionadas: 2000-2006, 2006-2009 y 2009-2012. En el apartado quinto se intenta profundizar en el conocimiento de los diferentes impactos que la crisis está causando en los municipios objeto de atención; se utiliza para ello un índice de vulnerabilidad del empleo a la crisis que relativiza el comportamiento de cada una de ellos con respecto a la media regional; se completa la investigación proponiendo una tipología que, a través de la relación entre la evolución experimentada por el número de afiliaciones a la Seguridad Social durante el periodo 2006-2012 y el número de afiliados respecto a la población en edad activa en el último año de referencia, permite establecer cuatro tipos de municipios según la forma en que han sido afectados por la crisis. Se recogen, por último, algunas conclusiones.

Es importante aclarar que este análisis sólo permite una primera aproximación al conocimiento del comportamiento urbano del empleo, que requiere completarse y matizarse en posteriores investigaciones con otras informaciones relacionadas tanto con los sectores de actividad en los que se integran los empleos, como con los tipos de contratos. A su vez, la limitada información disponible a esta escala de análisis exige ser completada mediante estudios de casos que permitan profundizar en las claves que ayudan a entender las diferentes formas en que está afectando la crisis a cada ciudad.

\section{ANDALUCÍA EN EL CONTEXTO ESPAÑOL. LA DESIGUAL INCIDENCIA DE LA CRISIS EN LAS REGIONES ESPAÑOLAS}

La realidad socioeconómica andaluza ha ido evolucionado a través de fuertes contrastes, de tal modo que a pesar de que en las coyunturas expansivas se han observado en la región comportamientos más dinámicos que los de la media española, en las etapas recesivas ha evolucionado más negativamente que el conjunto nacional (Castells-Hall, 1991; Aurioles, 1995; Zoido et al, 2001; Zoido-Caravaca, 2005; Pita-Pedregal, 2011). Cuando se inició la crisis la estructura económica andaluza seguía caracterizada por el predominio de actividades intensivas en recursos genéricos y basadas en el uso de trabajo poco cualificado; entre las mismas, destaca el excesivo crecimiento alcanzado por la construcción durante la segunda mitad de los noventa y los primeros años del siglo XXI, que ha influido muy negativamente en la actual crisis económica contribuyendo, además, a provocar un creciente desorden territorial (Fernández Tabales, 2012; Burriel, 2014; Fernández Tabales-Cruz, E. 2014).

Especial gravedad sigue revistiendo la ya tradicional incapacidad mostrada por la economía andaluza para generar suficiente número de empleos, lo que se ha convertido en un problema estructural de primer orden que se ha venido manteniendo a lo largo del tiempo hasta incluso en períodos de expansión económica. No hay que olvidar que este problema afecta también, aunque en menor medida, al conjunto del Estado.

En efecto, en España en general y muy especialmente en Andalucía, el desarrollo de los sectores secundario y terciario, ocurrido durante la etapa desarrollista de los años sesenta, fue incapaz de absorber a los efectivos expulsados del campo, provocando así una corriente emigratoria tanto hacia otros países, principalmente europeos, como hacia otras regiones españolas. La crisis de los setenta y la reestructuración productiva de inicios de los ochenta -que coincidió además con la vuelta de muchos emigrantes y la progresiva incorporación de la mujer al trabajo- no hicieron sino acentuar la incapacidad del sistema productivo para 
generar empleo (Etxezarreta, 1991; Toharia, 1992; Castaño, 1994; Méndez, 1998). Estos procesos se vieron acrecentados en Andalucía donde, por una parte, fue más duro el proceso de desagrarización, dada la mayor dependencia de la región al sector agrario, y, por otra, la reconversión industrial no se vio acompañada del desarrollo de actividades más competitivas; de este modo, han ido acrecentándose los problemas de inserción laboral que no estaban ni mucho menos resueltos al iniciarse la crisis. Como consecuencia de todo lo anterior, la economía andaluza se caracteriza por una mayor incapacidad que la de otras regiones para generar un número suficiente de puestos de trabajo (Delgado Cabeza, 1981, 2002 y 2006; Ferraro, 1990; Aurioles, 1995).

Entre las múltiples razones que han servido para explicar este comportamiento del mercado de trabajo en Andalucía destaca la que sostiene que su crecimiento económico nunca ha sido auto-centrado, sino que, por el contrario, ha dependido siempre de las exigencias de acumulación de regiones centrales como Cataluña y el País Vasco (Delgado Cabeza, 1981, 2002 y 2006). Teniendo en cuenta lo anterior, para entender mejor los impactos de la crisis en el empleo andaluz, parece oportuno empezar analizando su posición respecto a otras regiones españolas.

Según muestra la tabla 1, la incidencia de la crisis en el empleo está siendo muy fuerte habiéndose reducido un 10\% el número de afiliaciones a la Seguridad Social en 2012 respecto a 2006. Andalucía muestra un comportamiento próximo al nacional aunque algo menos negativo, pues la pérdida de trabajadores fue ligeramente inferior $(-9,35 \%)$; no hay que olvidar que esta región partía de una situación más desfavorable en términos de empleo, y que éste era ya tan insuficiente que difícilmente podía reducirse más. También se observan comportamientos menos negativos que la media en otras regiones: unas, por las mismas razones ya expuestas para Andalucía (por ejemplo, Extremadura y Galicia) y otras, porque partían de una situación económica mejor (País Vasco, Navarra, Comunidad de Madrid...). Los peores comportamientos se observan en las Comunidades de Valencia, Canarias, Murcia, Cataluña, Castilla-La Mancha e Islas Baleares; con la salvedad de Castilla-La Mancha donde el crecimiento inmobiliario de varias de sus provincias estuvo condicionado por la cercanía a Madrid, se trata de regiones litorales o insulares con un importante desarrollo del turismo que han conocido una intensa actividad inmobiliaria vinculada a la construcción de hoteles, apartamentos y segundas residencias. Las particularidades territoriales de las dos ciudades autónomas de Ceuta y Melilla, que derivan en un peso del empleo público tal que llega a concentrar en torno al 50\% de los asalariados, pueden explicar que sean los únicos ámbitos del país con una evolución positiva del número de afiliaciones (INE, Encuesta de Población Activa).

Se observa mejor la desigual incidencia de la crisis en las regiones españolas utilizando un índice de vulnerabilidad a la crisis que, partiendo de la propuesta realizada por Martín (2012) para el Reino Unido y aplicada por Sánchez Hernández (2013) en España, relaciona la evolución del empleo en cada comunidad autónoma con la del conjunto del Estado. Mientras que en las regiones cuyo índice supera el valor 1 (que es el que corresponde a España) el empleo ha sido menos sensible a la crisis que en el conjunto del país, aquellas que cuentan con valores del índice menores que la unidad han experimentado importantes pérdidas de puestos de trabajo, poniéndose con ello en evidencia su mayor vulnerabilidad. Según puede observarse en la tabla 1, este índice vuelve a evidenciar cómo el empleo se ha mostrado más sensible a la crisis en las Comunidades Autónomas de Valencia, Canarias y Murcia, mientras que Cata- 
luña, Castilla-La Mancha e Islas Baleares han desarrollado un comportamiento más próximo al nacional. Por el contrario, con la salvedad de Madrid, aquellas regiones cuyos empleos se han reducido en menor medida tienen en común, en la mayoría de los casos, contar con un empleo vinculado al sector primario o secundario de mayor peso que en otras regiones.

Tabla 1

EVOLUCIÓN DEL NÚMERO DE AFILIACIONES A LA SEGURIDAD SOCIAL POR COMUNIDADES AUTÓNOMAS

\begin{tabular}{|c|c|c|c|c|c|}
\hline $\begin{array}{c}\text { Comunidades } \\
\text { Autónoma }\end{array}$ & Afiliaciones 2006 & Afiliaciones 2012 & $\begin{array}{c}\text { Evolución } \\
2006-2012 \\
(2006=100)\end{array}$ & $\begin{array}{c}\text { Índice de } \\
\text { vulnerabilidad }^{4} \\
(2006-2012)\end{array}$ & $\begin{array}{c}\text { Afiliaciones/ } \\
\text { población en } \\
\text { edad activa } \\
2012^{5}\end{array}$ \\
\hline Andalucía & $3.022 .700(16,25 \%)$ & $2.740 .200(16,37 \%)$ & $-9,35 \%$ & 1,01 & $47,49 \%$ \\
\hline Aragón & $557.000(3,00 \%)$ & $511.300(3,05 \%)$ & $-8,20 \%$ & 1,02 & $57,32 \%$ \\
\hline Asturias & $386.700(2,08 \%)$ & $355.600(2,12 \%)$ & $-8,04 \%$ & 1,02 & $49,59 \%$ \\
\hline Illes Balears & $441.300(2,37 \%)$ & $395.800(2,36 \%)$ & $-10,31 \%$ & 1,00 & $50,39 \%$ \\
\hline Canarias & $773.400(4,16 \%)$ & $656.400(3,92 \%)$ & $-15,13 \%$ & 0,94 & $43,54 \%$ \\
\hline Cantabria & $218.700(1,18 \%)$ & $203,1(1,21 \%)$ & $-7,13 \%$ & 1,03 & $50,56 \%$ \\
\hline Castilla-León & $935.500(5,03 \%)$ & $872,6(5,21 \%)$ & $-6,72 \%$ & 1,04 & $52,76 \%$ \\
\hline $\begin{array}{l}\text { Castilla - La } \\
\text { Mancha }\end{array}$ & $710.600(3,82 \%)$ & $631,3(3,77 \%)$ & $-11,16 \%$ & 0,99 & $44,42 \%$ \\
\hline Cataluña & $3.331 .300(17,91 \%)$ & $2.954 .600(17,65 \%)$ & $-11,31 \%$ & 0,99 & $57,93 \%$ \\
\hline C. Valenciana & $1.936 .700(10,41 \%)$ & $1.589 .000(9,49 \%)$ & $-17,95 \%$ & 0,91 & $45,86 \%$ \\
\hline Extremad. & $381.100(2,05 \%)$ & $367.900(2,20 \%)$ & $-3,46 \%$ & 1,07 & $49,98 \%$ \\
\hline Galicia & $1.032 .500(5,55 \%)$ & $941.200(5,62 \%)$ & $-8,84 \%$ & 1,01 & $51,74 \%$ \\
\hline C. Madrid & $2.926 .600(15,74 \%)$ & $2.718 .800(16,24 \%)$ & $-7,10 \%$ & 1,03 & $60,52 \%$ \\
\hline Murcia & $573.200(3,08 \%)$ & $493.800(2,95 \%)$ & $-13,85 \%$ & 0,96 & $49,20 \%$ \\
\hline Navarra & $269.700(1,45 \%)$ & $253.800(1,52 \%)$ & $-5,90 \%$ & 1,05 & $59,14 \%$ \\
\hline País Vasco & $933.200(5,02 \%)$ & $896.000(5,35 \%)$ & $-3,99 \%$ & 1,07 & $61,45 \%$ \\
\hline Rioja, La & $129.500(0,70 \%)$ & $117.600(0,70 \%)$ & $-9,19 \%$ & 1,01 & $54,58 \%$ \\
\hline Ceuta & $18.300(0,10 \%)$ & $19.900(0,12 \%)$ & $8,74 \%$ & 1,21 & $34,63 \%$ \\
\hline Melilla & $18.100(0,10 \%)$ & $19.600(0,12 \%)$ & $8,29 \%$ & 1,20 & $35,65 \%$ \\
\hline $\begin{array}{l}\text { TOTAL } \\
\text { ESPAÑA }\end{array}$ & $18.596 .300(100,00 \%)$ & $\begin{array}{l}16.738 .500 \\
(100,00 \%)\end{array}$ & $-9,99 \%$ & $\mathbf{1 , 0 0}$ & $52,34 \%$ \\
\hline
\end{tabular}

Fuente: Movimiento Laboral Registrado, INE. Elaboración propia.

4 El Índice de vulnerabilidad del empleo a la crisis se obtiene de la siguiente fórmula: (empleo en cada región 2012/empleo en cada región 2006) / (empleo España 2012/empleo España 2006).

5 Teniendo en cuenta que a escala municipal no existen datos sobre población activa en los años estudiados, para poder comparar mejor lo que ocurre a escalas regional y municipal, se utiliza la población en edad de trabajar, es decir la que tiene entre 16 y 65 años. 
Para profundizar en el análisis de las afiliaciones a la Seguridad Social se introduce un nuevo matiz relacionando éstas con la población en edad activa (\%), lo que ayuda a conocer las diferencias interregionales respecto a la situación actual del empleo. Como muestra la tabla 1, la mayoría de las regiones que cuentan con valores por encima de la media nacional en 2012 son las que tradicionalmente han disfrutado de mayores niveles de desarrollo; es el caso de País Vasco, Madrid, Navarra, Cataluña y La Rioja y, en menor medida, Aragón y Castilla y León. A diferencia de ello, aquellas otras con porcentajes inferiores al 50\% coinciden, en su mayoría, con las Comunidades Autónomas que han tenido más problemas estructurales para la generación de empleo: Castilla-La Mancha, Valencia, Andalucía, Murcia, Asturias y Extremadura. Con ello se pone en evidencia que aunque la destrucción generalizada de empleo ha sido una constante tanto en unas regiones como en otras, las que partían de situaciones más favorables siguen siendo las mejor posicionadas.

\section{EFECTOS DE LA CRISIS EN EL EMPLEO DE LOS MUNICIPIOS URBANOS SEGÚN TAMA- ÑOS POBLACIONALES}

Los procesos generales afectan con diferente intensidad y forma a espacios concretos en estrecha relación con las características económicas, sociales, laborales, institucionales y territoriales heredadas por cada uno de ellos, así como por las políticas públicas aplicadas y la capacidad mostrada por los agentes locales, ya sean éstos públicos o privados, para reaccionar y buscar soluciones con las que hacer frente a sus problemas. No puede extrañar, por tanto, que la incidencia de la crisis en las ciudades que forman parte de esta Comunidad Autónoma esté siendo muy diversa.

Según puede observarse en la tabla 2, sigue existiendo un desequilibrio económico entre los municipios que conforman el sistema territorial andaluz, puesto que sólo en los que superan los 100.000 habitantes el peso relativo de las actividades económicas, medido a través del empleo que éstas generan, es mayor que el de la población.

Los cambios que se han ido produciendo a lo largo del tiempo muestran claramente distintos grados de incidencia de la crisis según tamaño poblacional. Investigaciones precedentes indicaron que, durante la etapa económicamente expansiva (2000-2006), el crecimiento más significativo se produjo en aquellos municipios cuya población oscilaba entre los 20.000 y 100.000 habitantes, poniéndose en evidencia la positiva evolución experimentada por las actividades económicas en ciudades clasificadas como medias cuya presencia es clave para el equilibrio del sistema urbano andaluz y, en consecuencia, para los procesos de desarrollo territorial (Caravaca-González-Mendoza-Silva, 2009). Como contrapunto a lo anterior, durante la etapa recesiva (2006-2012) los comportamientos de los distintos tamaños municipales no han seguido esta tendencia. Efectivamente, durante los primeros años de la crisis (2006-2009) siguió creciendo el empleo en los municipios urbanos de menos de 50.000 habitantes, mientras que la pérdida de puestos de trabajo era directamente proporcional al volumen de población; no obstante, se han ido produciendo ciertos cambios durante el siguiente periodo (2009-2012) en el que las pérdidas de empleo afectan ya, aunque con distintas intensidades, a todos los municipios urbanos, con independencia de su tamaño. 
Tabla 2

AFILIACIONES A LA SEGURIDAD SOCIAL POR TAMAÑOS POBLACIONALES

\begin{tabular}{|l|r|c|c|r|r|}
\hline Tamaño municipal & $\begin{array}{c}\text { Número de } \\
\text { municipios }\end{array}$ & $\begin{array}{c}\text { Población } \\
\mathbf{2 0 1 2}\end{array}$ & $\begin{array}{c}\text { Afiliaciones } \\
\mathbf{2 0 1 2}\end{array}$ & $\begin{array}{c}\text { Afiliaciones } \\
\mathbf{2 0 0 6 - 2 0 0 9} \\
(\mathbf{2 0 0 6}=\mathbf{1 0 0})\end{array}$ & $\begin{array}{c}\text { Afiliaciones } \\
\mathbf{2 0 0 9 - 2 0 1 2} \\
(\mathbf{2 0 0 9 = 1 0 0 )}\end{array}$ \\
\hline $10.001-20.000$ & 71 & $\begin{array}{c}1.031 .221 \\
(12,20 \%)\end{array}$ & $\begin{array}{c}267.837 \\
(10,05 \%)\end{array}$ & 127,22 & 92,64 \\
\hline $20.001-50.000$ & 52 & $\begin{array}{c}1.449 .103 \\
(17,15 \%)\end{array}$ & $\begin{array}{c}402.004 \\
(15,09 \%)\end{array}$ & 116,87 & 93,95 \\
\hline $50.001-100.000$ & 17 & $\begin{array}{c}1.258 .681 \\
(14,90 \%)\end{array}$ & $\begin{array}{c}290.670 \\
(10,91 \%)\end{array}$ & 99,02 & 92,86 \\
\hline $100.001-250.000$ & 9 & $\begin{array}{c}1.417 .791 \\
(16,78 \%)\end{array}$ & $\begin{array}{c}536.492 \\
(20,14 \%)\end{array}$ & 96,35 & 92,72 \\
\hline$>250.000$ & 3 & $\begin{array}{c}1.598 .629 \\
(18,92 \%)\end{array}$ & $\begin{array}{c}638.163 \\
(23,96 \%)\end{array}$ & 95,40 & 93,09 \\
\hline Total municipios & $\mathbf{1 5 2}$ & $\begin{array}{c}\mathbf{6 . 7 5 5 . 4 2 5} \\
(\mathbf{7 9 , 9 5 \% )}\end{array}$ & $\begin{array}{c}\mathbf{2 . 1 3 5 . 1 6 6} \\
(\mathbf{8 0 , 1 5 \%})\end{array}$ & $\mathbf{1 0 2 , 9 4}$ & $\mathbf{9 3 , 0 7}$ \\
\hline urbanos & $\mathbf{7 7 1}$ & $\begin{array}{c}\mathbf{8 . 4 4 9 . 9 8 5} \\
(\mathbf{1 0 0 \%})\end{array}$ & $\begin{array}{c}\mathbf{2 . 6 6 3 . 9 4 2} \\
(\mathbf{1 0 0 \%})\end{array}$ & $\mathbf{9 2 , 7 5}$ & $\mathbf{9 4 , 3 9}$ \\
\hline Total Andalucía & & &
\end{tabular}

Fuente: Tesorería General de la Seguridad Social, Padrón Municipal de Habitantes, INE. Elaboración propia.

Como complemento a lo anterior, el statu quo del empleo en las ciudades a partir de la relación entre las afiliaciones a la Seguridad Social y la población en edad activa (\%) resulta un indicador especialmente significativo. Como muestra la tabla 3, tanto entre los valores máximos como entre los mínimos destacan los municipios mayores, y otro tanto ocurre en

Tabla 3

AFILIACIONES A LA SEGURIDAD SOCIAL EN RELACIÓN A LA POBLACIÓN EN EDAD ACTIVA (15-65 AÑOS) POR TAMAÑOS POBLACIONALES (2012)

\begin{tabular}{|l|c|c|c|c|c|}
\hline $\begin{array}{c}\text { Tamaño } \\
\text { municipal }\end{array}$ & $\begin{array}{c}\text { Valor } \\
\text { máximo }\end{array}$ & $\begin{array}{c}\text { Valor } \\
\text { mínimo }\end{array}$ & Media & $\begin{array}{c}\mathbf{N}^{\mathbf{0}} \text { ciudades cuya } \\
\text { relación entre afiliados/ } \\
\text { población en edad de } \\
\text { trabajar es superior al } \\
\mathbf{5 0 \%}\end{array}$ & $\begin{array}{c}\mathbf{N}^{\mathbf{0}} \text { ciudades cuya } \\
\text { relación entre } \\
\text { afiliados/población en } \\
\text { edad de trabajar es } \\
\text { inferior al 25\% }\end{array}$ \\
\hline $10.001-20.000$ & $69,87 \%$ & $17,14 \%$ & $37,89 \%$ & $14(19,72 \%)$ & $11(15,49 \%)$ \\
\hline $20.001-50.000$ & $68,24 \%$ & $19,44 \%$ & $40,24 \%$ & $11(21,15 \%)$ & $6(11,54 \%)$ \\
\hline $50.001-100.000$ & $65,75 \%$ & $19,05 \%$ & $33,24 \%$ & $1(5,88 \%)$ & $3(17,65 \%)$ \\
\hline $100.001-250.000$ & $82,71 \%$ & $31,52 \%$ & $55,14 \%$ & $6(66,67 \%)$ & 0 \\
\hline$>250.000$ & $64,27 \%$ & $51,81 \%$ & $58,57 \%$ & $3(100 \%)$ & 0 \\
\hline
\end{tabular}

Fuente: Tesorería General de la Seguridad Social. Elaboración propia. 
cuanto al valor medio. En todos los municipios de más de 250.000 habitantes los valores de la relación entre afiliados a la Seguridad Social y población en edad activa superan el 50\%, y en ninguno de los que tienen más de 100.000 habitantes dicha relación es inferior al 25\%. Los comportamientos son significativamente distintos en los otros tamaños urbanos, pues en éstos sólo veintiséis municipios cuentan con un porcentaje de afiliaciones a la Seguridad Social respecto a la población en edad activa superior al $50 \%$, mientras en veinte este valor es inferior al 25\%. El mayor dinamismo y diversificación económica de los municipios con más población pueden explicar estas diferencias de comportamientos.

\section{DISTRIBUCIÓN TERRITORIAL DE LOS IMPACTOS DE LA CRISIS SOBRE EL EMPLEO}

Para profundizar en el análisis de los impactos territoriales generados por la crisis se han elaborado los mapas de la figura 2, que recogen la evolución experimentada por el empleo, medido a través del número de afiliaciones a la Seguridad Social, en los municipios urbanos desde el año 2000 al 2012. Como puede comprobarse, en Andalucía se ha producido un cambio radical en cuanto al comportamiento del empleo, pues la crisis rompe con su generalizada evolución positiva, mostrando como contrapunto un panorama desolador en las dos etapas en que se ha dividido la crisis.

Resulta bastante ilustrativo que durante el periodo 2000-2006 crecieran los puestos de trabajo en la práctica totalidad de los municipios, siendo solamente en dos, Medina Sidonia en Cádiz y La Puebla del Río en Sevilla, en los que se reduce el número de afiliados (Figura 2A). De signo muy distinto es el mapa correspondiente al inicio de la crisis, siendo ya en éste muy numerosos los municipios que pierden afiliados, mientras aumentan sólo en veinticinco que, en su mayor parte, son ciudades pequeñas y medias a las que hay que añadir dos capitales provinciales, Jaén y Cádiz. Se pone así de manifiesto que es la explosión de la burbuja inmobiliaria la principal responsable de las pérdidas de empleos que se producen fundamentalmente en los municipios litorales y en los que conforman las principales aglomeraciones urbanas. Excepcionales son los casos de Cádiz -donde el crecimiento del sector de la construcción se vio frenado por la escasez de suelo municipal-, y de los municipios costeros de Cartaya, Moguer y Almonte (Huelva), donde siguió creciendo el empleo después de iniciarse la crisis; en estos últimos la conformación de sistemas productivos de doble especialización (turismo y agricultura intensiva) les confiere una mayor capacidad de resistencia a la crisis (Figura 2B). En el mapa correspondiente a la segunda fase de la crisis, es decir a los años comprendidos entre 2009 y 2012, no se observan cambios significativos respecto al anterior, aunque son ya únicamente catorce los municipios en los que crecen las afiliaciones; merece la pena llamar la atención acerca de que la mitad de ellos, Estepa en Sevilla, Ubrique en Cádiz, Moguer y Almonte en Huelva, El Ejido, Vícar y Níjar en Almería, cuenten con sistemas productivos locales de diferente especialización (Figura 2C).

Para complementar lo observado en los mapas, se ha elaborado la tabla 4, que recoge el ranking de los municipios urbanos andaluces considerando la evolución relativa experimentada por el número de afiliaciones a la Seguridad Social entre 2006 y 2012, y pone aún más en evidencia los significativos contrastes existentes entre ellos. Así, llama la atención que sean los municipios no metropolitanos, cuya población oscila entre los 10.000 y 100.000 habitantes y donde la agricultura sigue teniendo un peso muy importante en sus estructu- 
Figura 2

EVOLUCIÓN DEL NÚMERO DE AFILIADOS A LA SEGURIDAD SOCIAL (2000-2012)

Figura $2 \mathrm{~A}$

EVOLUCIÓN ENTRE 2000 Y 2006

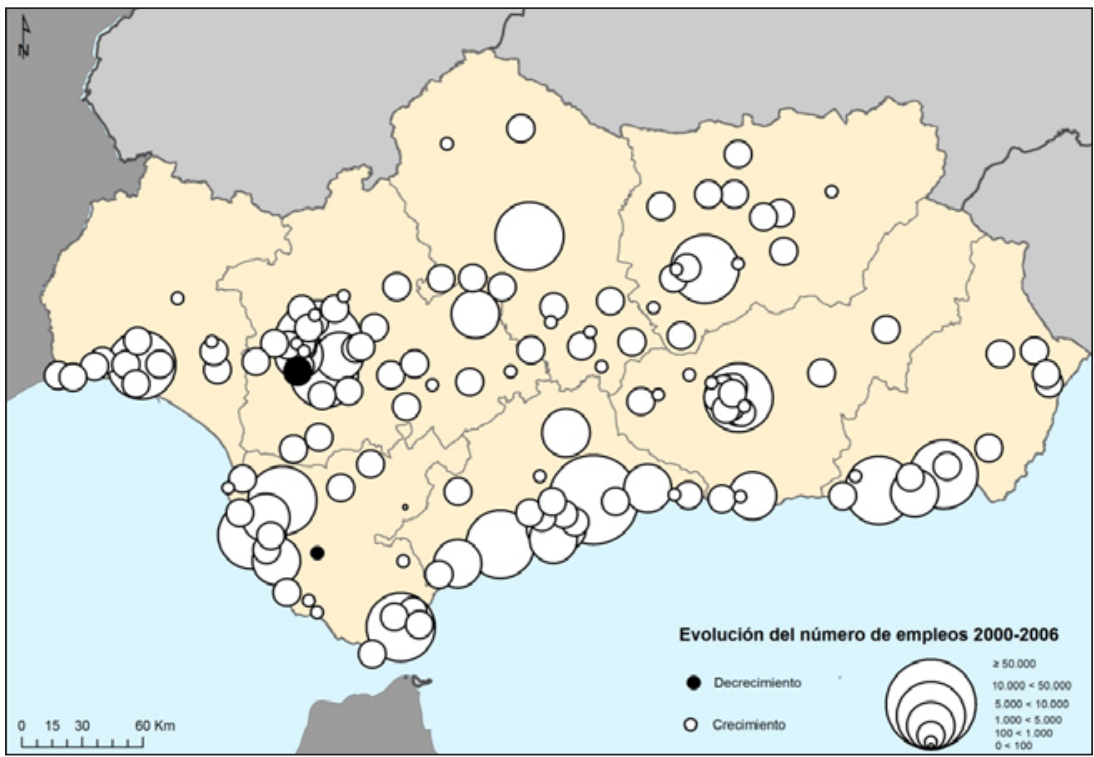

Figura $2 \mathrm{~B}$

EVOLUCIÓN ENTRE 2006 Y 2009

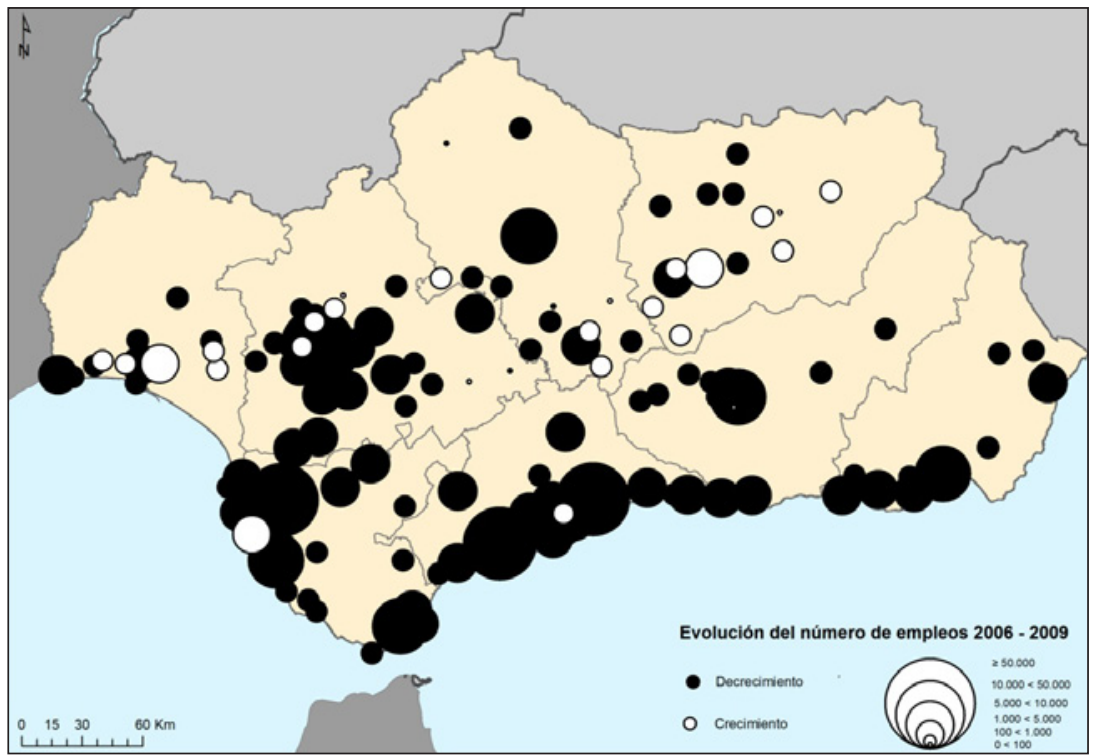




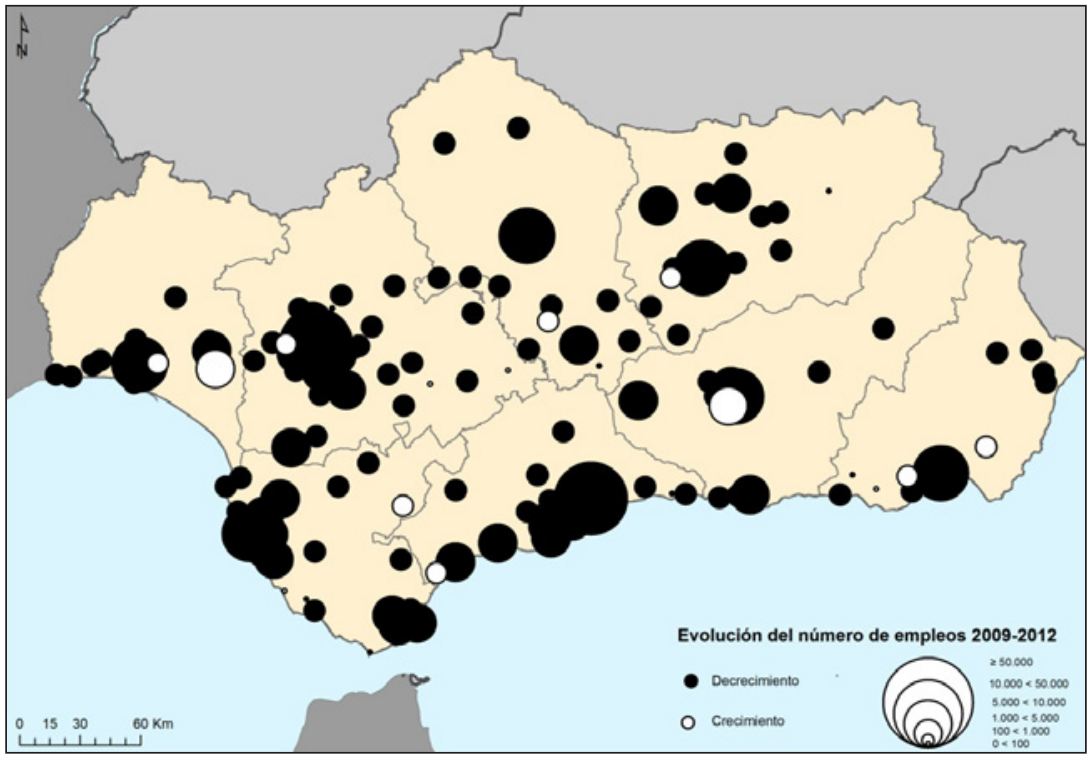

Fuente: Tesorería General de la Seguridad Social. Elaboración propia.

ras económicas, los que han soportado mejor los envites de la crisis (Jódar, Villacarrillo y Alcaudete en Jaén; Íllora en Granada; Moguer y Almonte en Huelva; Aguilar de la Frontera y Palma del Río en Córdoba y Cantillana en Sevilla). Aunque Brenes no se incluye en el grupo anterior, dado que forma parte de la aglomeración urbana de Sevilla, su economía sigue muy vinculada a la agricultura y también está resistiendo mejor la crisis. A diferencia de ello, la mayor destrucción de empleo ha tenido lugar en municipios que en buena parte están emplazados en las principales aglomeraciones urbanas y que, además, en su mayoría son costeros (Chiclana de la Frontera en la de Bahía de Cádiz-Jerez; Coín, Alhaurín el Grande y Fuengirola en la de Málaga; Peligros y Huétor-Vega en la de Granada; La Línea y San Roque en Bahía de Algeciras). Se confirma pues que tanto en el litoral como en las aglomeraciones urbanas la incidencia de la crisis ha sido mayor, lo que está relacionado con la fuerte actividad inmobiliaria habida en estos dos tipos de espacios, a lo que hay que añadir el hecho de que los servicios sociales básicos, muy afectados por la reducción de presupuestos, se encuentren especialmente concentrados en estos ámbitos.

Para profundizar en el análisis anterior, la tabla 5 recoge las 10 ciudades que más destacan positiva y negativamente según la relación entre el número de afiliados a la Seguridad Social y la población potencialmente activa en el año 2012. Entre las que alcanzan los valores más altos se incluyen: cuatro capitales provinciales; una cabecera comarcal (Antequera en Málaga); municipios que forman parte de aglomeraciones urbanas (caso de Peligros en Granada) y otros en los que la actividad agrícola es tan relevante que incluso llega a articular 
Tabla 4

MUNICIPIOS URBANOS CON COMPORTAMIENTOS EXTREMOS SEGÚN LA EVOLUCIÓN DE LAS AFILIACIONES A LA SEGURIDAD SOCIAL, 2006-2012 $(2006=100)$

\begin{tabular}{|l|l|l|r|}
\hline \multicolumn{2}{|c|}{$\begin{array}{c}\text { Las } 10 \text { ciudades con valores máximos de } \\
\text { crecimiento }\end{array}$} & \multicolumn{2}{c|}{$\begin{array}{c}\text { Las } 10 \text { ciudades con valores máximos de } \\
\text { decrecimiento }\end{array}$} \\
\hline Jódar (Jaén) & $319,22 \%$ & Chiclana de la Frontera (Cádiz) & $-39,98 \%$ \\
\hline Villacarrillo (Jaén) & $230,96 \%$ & Coín (Málaga) & $-30,35 \%$ \\
\hline Illora (Granada) & $181,30 \%$ & Huércal de Almería (Almería) & $-30,13 \%$ \\
\hline Moguer (Huelva) & $176,98 \%$ & Estepona (Málaga) & $-29,78 \%$ \\
\hline Aguilar de la Frontera (Córdoba) & $129,75 \%$ & Alhaurín el Grande (Málaga) & $-28,93 \%$ \\
\hline Brenes (Sevilla) & $125,65 \%$ & Fuengirola (Málaga) & $-24,97 \%$ \\
\hline Cantillana (Sevilla) & $120,45 \%$ & Peligros (Granada) & $-24,44 \%$ \\
\hline Palma del Río (Córdoba) & $112,52 \%$ & La Línea de la Concepción (Cádiz) & $-23,99 \%$ \\
\hline Alcaudete (Jaén) & $109,66 \%$ & Huétor Vega (Granada) & $-23,65 \%$ \\
\hline Almonte (Huelva) & $107,76 \%$ & San Roque (Cádiz) & $-23,49 \%$ \\
\hline
\end{tabular}

Fuente: Tesorería General de la Seguridad Social. Elaboración propia.

Tabla 5

MUNICIPIOS URBANOS CON COMPORTAMIENTOS EXTREMOS SEGÚN LA RELACIÓN ENTRE AFILIACIONES A LA SEGURIDAD SOCIAL Y POBLACIÓN EN EDAD ACTIVA (15-65 AÑOS) 2012

\begin{tabular}{|l|r|l|r|}
\hline \multicolumn{2}{|c|}{ Las 10 ciudades con valores máximos } & \multicolumn{2}{c|}{ Las 10 ciudades con valores mínimos } \\
\hline Cádiz & $82,71 \%$ & Las Gabias (Granada) & $17,14 \%$ \\
\hline Jaén & $76,05 \%$ & La Línea de la Concepción (Cádiz) & $19,05 \%$ \\
\hline Peligros (Granada) & $69,87 \%$ & Huétor- Vega (Granada) & $19,39 \%$ \\
\hline Granada & $69,63 \%$ & Barbate (Cádiz) & $19,44 \%$ \\
\hline Antequera (Málaga) & $68,24 \%$ & San Fernando (Cádiz) & $19,76 \%$ \\
\hline Moguer (Huelva) & $67,32 \%$ & La Algaba (Sevilla) & $20,04 \%$ \\
\hline Almonte (Huelva) & $65,84 \%$ & Coria del Río (Sevilla) & $21,99 \%$ \\
\hline Jódar (Jaén) & $65,80 \%$ & Chiclana de la Frontera (Cádiz) & $22,06 \%$ \\
\hline El Ejido (Almería) & $65,75 \%$ & Rincón de la Victoria (Málaga) & $22,20 \%$ \\
\hline Sevilla & $64,27 \%$ & Aljaraque (Huelva) & $22,39 \%$ \\
\hline
\end{tabular}

Fuente: Padrón Municipal de Habitantes, INE, Tesorería General de la Seguridad Social. Elaboración propia.

sus sistemas productivos (El Ejido en Almería, y Almonte y Moguer en Huelva, y Jódar en Jaén). Llama especialmente la atención el caso de Cádiz, donde el alto valor de la relación sólo se explica por la presencia de empleos vinculados a las administraciones públicas, al tratarse de una capital de provincia, así como los relacionados con la existencia de un importante puerto; se pone con ello de manifiesto que la ciudad da empleo a habitantes de otros municipios de la aglomeración. Por el contrario, es anormalmente baja la cifra corres- 
pondiente a la población potencialmente activa (que es la que conforma el denominador de la relación), lo que se explica por los límites impuestos al crecimiento urbano por la escasa superficie de suelo del municipio, que ha condicionado el crecimiento del número residentes. Todas las ciudades peor posicionadas son costeras o forman parte de aglomeraciones urbanas lo que, una vez más, pone en evidencia los impactos causados en el empleo por el desmedido crecimiento del sector inmobiliario. Es necesario destacar sobre todo los casos de La Línea de la Concepción y Chiclana de la Frontera en Cádiz, y Huétor-Vega en Granada, ya que estas tres ciudades también están incluidas en aquellas en las que el empleo ha experimentado un mayor decrecimiento relativo.

\section{LA SENSIBILIDAD DEL EMPLEO URBANO A LA CRISIS}

Con objeto de observar mejor la diferente intensidad con que está incidiendo la crisis en el empleo de las ciudades andaluzas se utiliza el índice de vulnerabilidad ${ }^{6}$, ya antes utilizado para las regiones españolas, que relaciona ahora la evolución del número de afiliados a la Seguridad Social en cada municipio urbano con respecto a la del conjunto de Andalucía.

Según se observa en la figura 3 son diecisiete los municipios cuyo índice de vulnerabilidad es inferior a 0,90 , siendo éstos, por tanto, los más amenazados por la crisis; se localizan en la costa o muy cercanos a ella donde, como se ha venido señalando, los procesos urbanizadores han sido más potentes.

Junto a los anteriores, otros veintiuno cuentan también con valores del índice que quedan por debajo de la unidad; forman parte de este grupo un buen número de municipios ubicados en las coronas metropolitanas de Sevilla, Málaga y Granada, así como en el litoral. También en estos casos puede explicarse el comportamiento de su empleo por el estallido de la burbuja inmobiliaria, vinculado a la construcción de primeras residencias en los municipios de las coronas metropolitanas, o de viviendas secundarias, en el litoral. Junto a lo anterior, hay que considerar también el efecto producido por el cierre de industrias que actuaron como motrices y articuladoras de un tejido empresarial auxiliar -como sucedió en Linares o la Carolina con Santana-Motor- o por la profundización del declive industrial iniciado ya antes de la crisis en Los Barrios y San Fernando (Figura 3).

Con valores del índice en torno a la media, se identifican municipios localizados sobre todo a lo largo del Valle del Guadalquivir, aunque también destacan algunos costeros; es en este grupo donde se encuentran las ocho capitales provinciales, además de algunas de las ciudades que conforman sus entornos metropolitanos. En buena parte de los municipios que integran este grupo, el sector agrario tiene una gran importancia económica, destacando los casos de El Ejido y Vícar; en otros, se desarrollan ciertas industrias que, en el caso de Lucena, Estepa, Ubrique, Valverde del Camino y Mancha Real, han llegado a conformar distritos industriales (Figura 3).

Por su parte, son diecisiete los municipios que se han visto menos afectados por la crisis a tenor de los valores del índice $(\geq 2)$. La mayoría cuenta con una economía de base agraria destacando, por ejemplo, las actividades relacionadas con el cultivo del olivar en íllora

6 El Índice de vulnerabilidad del empleo a la crisis se obtiene de la siguiente fórmula: (empleo en cada municipio 2012/empleo en cada municipio 2006) / (empleo Andalucía 2012/empleo Andalucía 2006). 
(Granada), Alcaudete, Jódar y Villacarrillo (Jaén); las vinculadas al naranjo en Palma del Río (Córdoba), Brenes y Lora del Río (Sevilla); y a la producción de espárragos en Huétor-Tájar (Granada). En otros, como Almonte, Moguer, Cartaya (Huelva) y Níjar (Almería) el turismo sirve como complemento a las actividades agrarias, en el primer caso relacionadas con la producción de frutas (fresas, frambuesas, arándanos...) y en el segundo con hortalizas de invernadero (Figura 3).

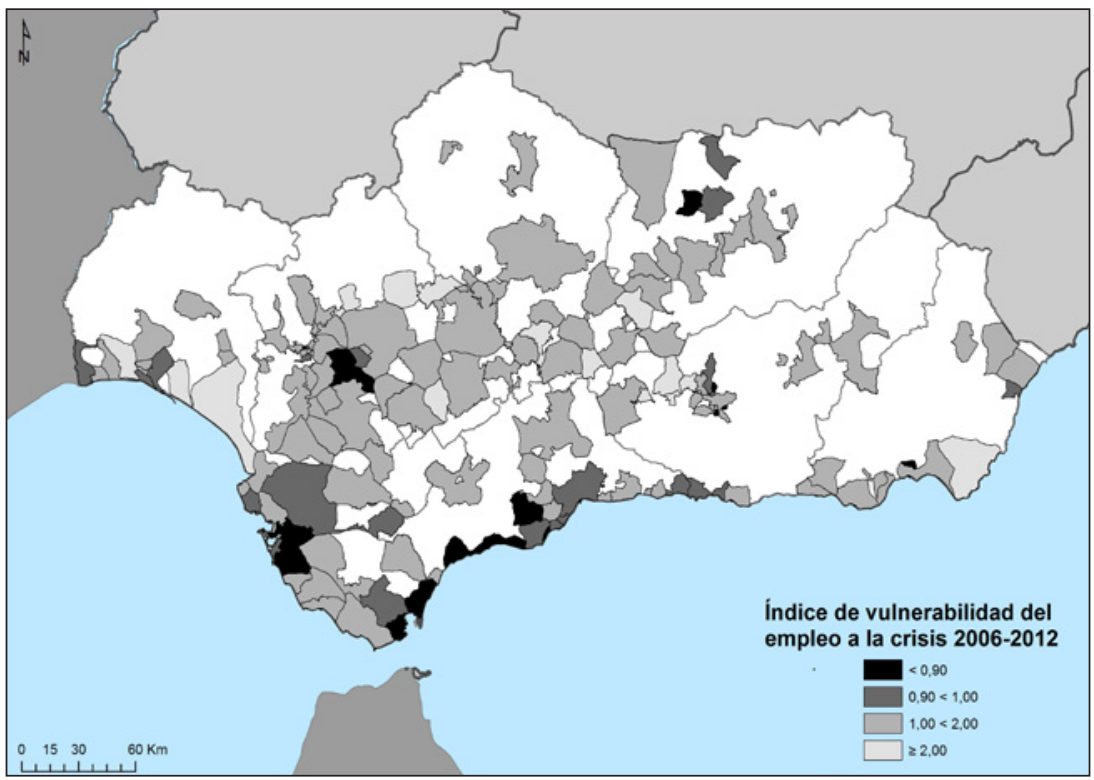

Fuente: Tesorería General de la Seguridad Social. Elaboración propia.

Por último, para completar el análisis sobre los efectos territoriales de la crisis según el comportamiento del empleo, se ha realizado una tipología que vincula la evolución del número de afiliaciones a la Seguridad Social entre 2006 y 2012 con el porcentaje de afiliaciones respecto a la población en edad activa en el último año de referencia. Fruto de esta asociación se identifican cuatro situaciones diferentes respecto a los promedios regionales (Tabla 6):

- Los municipios que responden al tipo A alcanzan valores por encima de la media andaluza en ambos indicadores.

- Forman parte del tipo B los que han conocido una evolución de las afiliaciones más positiva que la del conjunto de la región, aunque cuentan con un porcentaje de afiliaciones en relación a la población en edad activa inferior al promedio andaluz.

- Se incluyen en el tipo C los municipios que, pese a haber conocido una evolución del número de afiliaciones más negativa que la media regional, alcanzan en 2012 cifras superiores de afiliaciones respecto a la población en edad activa. 
- Conforman, por último, el tipo D aquellos en los que las cifras correspondientes a los dos indicadores utilizados se sitúan por debajo de ambos promedios.

Tabla 6

TIPOLOGÍA DE MUNICIPIOS URBANOS SEGÚN LOS IMPACTOS DE LA CRISIS SOBRE EL EMPLEO

\begin{tabular}{|c|c|c|c|}
\hline TIPO & $\begin{array}{c}\text { Evolución afiliaciones } \\
\mathbf{2 0 0 6 - 2 0 1 2}\end{array}$ & $\begin{array}{c}\text { Afiliaciones/Población } \\
\text { edad activa, 2012 }\end{array}$ & $\mathbf{N}^{\text {0 Ciudades }}$ \\
\hline A & + & + & 38 \\
\hline B & + & - & 75 \\
\hline C & - & + & 6 \\
\hline D & - & - & 33 \\
\hline
\end{tabular}

Fuente: Tesorería General de la Seguridad Social, Padrón Municipal de Habitantes, INE. Elaboración propia.

La figura 4 muestra la distribución territorial de esta tipología. Entre los treinta y ocho municipios que forman parte del tipo A se incluyen las capitales provinciales, excepto Huelva y Málaga, así como un buen número de las llamadas agro-ciudades, algunas de las cuales son también cabeceras comarcales; entre ellas cabe citar a Osuna y Lebrija (Sevilla), Antequera (Málaga), Rute, Priego de Córdoba y Baena (Córdoba). También se incluyen en el grupo que mejor se comporta los municipios de El Ejido, Nícar y Víjar que, como es sabido, están especializados en cultivos de invernadero (Figura 4).

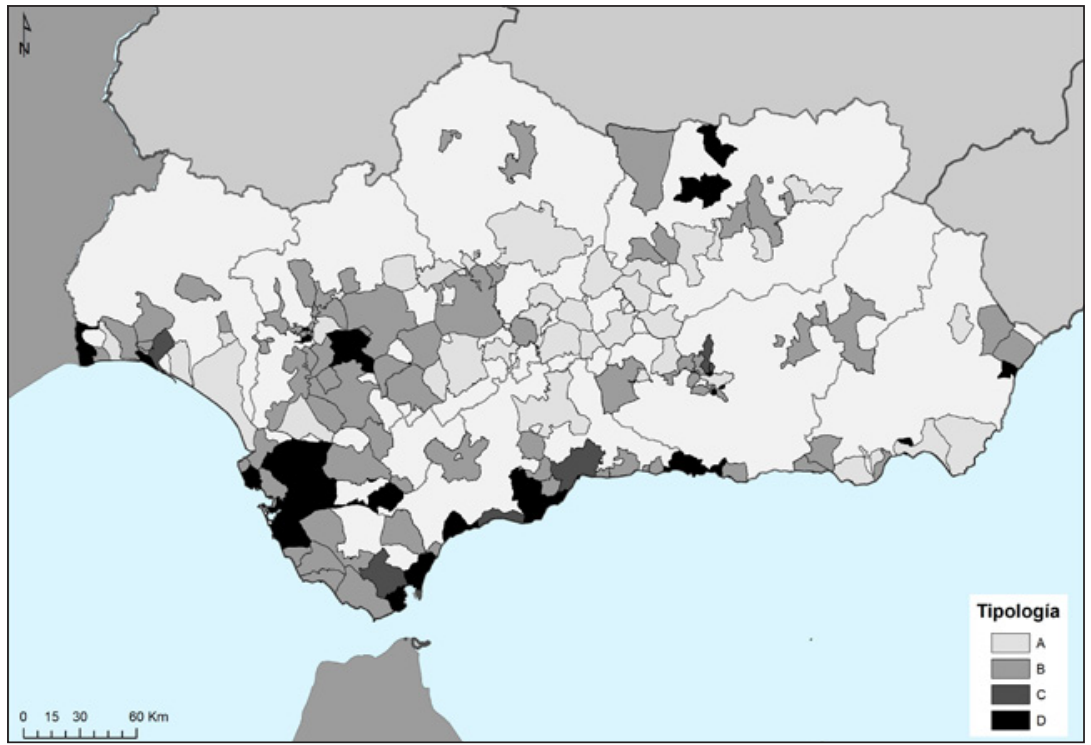

Fuente: Tesorería General de la Seguridad Social. Elaboración propia. 
Como contrapunto a lo anterior, son treinta y tres los municipios que se incluyen en el tipo D que, además de haber soportado una mayor destrucción del empleo, cuentan con valores de afiliados respecto a la población en edad activa inferiores a la media regional; en su mayoría se localizan en la costa, lo que viene a demostrar, una vez más, el impacto generado por la caída del sector de la construcción. Llama bastante la atención que municipios del interior con una mayor presencia de la industria en sus economías y que se habían venido comportando de forma bastante dinámica, como son los casos de Alcalá de Guadaíra en Sevilla, y de Linares y Bailén en Jaén, cumplan ahora las condiciones establecidas en este cuarto tipo (Figura 4).

El número de municipios urbanos que se reparte entre los dos tipos intermedios, B y C, es muy desigual, pues mientras setenta y cinco se comportan según lo establecido en el tipo B, son sólo seis los que cumplen las características del C. Respecto a los primeros, como puede observarse en el mapa en su mayoría se concentran en las coronas metropolitanas de Sevilla (La Rinconada, S. Juan de Aznalfarache, Tomares...) y Granada (Santa Fe, Churriana, Armilla...) o bien se distribuyen difusamente por toda la región (Figura 4). Entre los seis incluidos en el tipo $\mathrm{C}$ se encuentran las capitales provinciales de Huelva y Málaga, dos ciudades costeras, Marbella en Málaga y Los Barrios en Bahía de Algeciras, y otras dos metropolitanas Peligros y Albolote en Granada (Figura 4); se trata en todos los casos de ámbitos con una significativa presencia de actividades industriales y/o de servicios.

\section{ALGUNAS CONCLUSIONES}

La crisis financiera está poniendo de manifiesto toda una serie de contradicciones asociadas tanto a la forma en que se ha producido el proceso de globalización y a los fundamentos que han sustentado el modelo de crecimiento económico neocapitalista, como a las políticas que se están implementando y que, según se argumenta, pretenden controlar los impactos negativos por ella generados. No puede extrañar, en consecuencia, que sean muchos los investigadores interesados en analizarla. Resulta llamativo, sin embargo, que sea tan limitado el número de los que se centran en el estudio de sus efectos territoriales utilizando como unidad espacial de referencia el municipio; y ello a pesar de que dicha escala es la que permite observar con más nitidez las diferencias existentes en las formas en que incide la crisis en los territorios y, en consecuencia, en las diversas estrategias que deben ser implementadas para corregir sus efectos indeseados.

Aunque, dada la complejidad de los procesos en curso y la insuficiente perspectiva temporal con que aún se cuenta, resulta difícil y prematuro sacar conclusiones acerca de las transformaciones territoriales derivadas de la crisis estructural que nos afecta, sí pueden señalarse algunas diferencias interurbanas que pueden permitir detectar algunos posibles cambios en las formas de articulación territorial.

Como es sabido, España se encuentra entre los países más afectados por una crisis que incluye entre sus principales impactos una importante destrucción de empleo. Especialmente preocupante es el caso de Andalucía, comunidad autónoma que no sólo está perdiendo un elevado número de puestos de trabajo, sino que ya antes de que se iniciara la crisis era una de las menos capacitadas para generar un número suficiente de ellos. 
Los impactos que sobre el empleo está teniendo la crisis en Andalucía no han alterado hasta ahora significativamente la estructura jerárquica de su sistema urbano. Pese a lo anteriormente apuntado, se observan algunos cambios en los municipios que tienen entre 10.000 y 50.000 habitantes, intervalo en el que se incluye la mayoría de las agro-ciudades, lo que puede ser un primer indicio de ciertas transformaciones en el sistema urbano regional. Se reactiva, así de nuevo, el papel ejercido por las agro-ciudades en la economía y en el sistema urbano regional, muy potente históricamente, pero que fue perdiendo vigencia a partir de la década de los setenta del pasado siglo, al acentuarse el crecimiento de los servicios con la consiguiente pérdida del peso relativo de las actividades agrarias.

Junto a lo anterior, el análisis de la evolución experimentada por el comportamiento urbano del empleo desde principios del siglo XXI permite apreciar cambios que, a escala local, resultan significativos. La utilización de un índice de vulnerabilidad a la crisis que relaciona la evolución de cada municipio con la del conjunto de Andalucía y de una tipología que distingue entre cuatro tipos de comportamientos, permiten matizar sobre los diferentes grados y formas con que está afectando la crisis al empleo de los municipios urbanos.

En este último sentido, puede concluirse que las ciudades cuyo empleo está siendo más vulnerable a la crisis se localizan sobre todo en las aglomeraciones urbanas y en las zonas costeras, lo que puede explicarse por el fuerte impacto provocado en ellas por el estallido de la burbuja inmobiliaria. Hay que sumar a lo anterior la destrucción de empleo provocada por las políticas económicas que se están implementando, que ha supuesto una reducción de servicios públicos que se localizan, en buena parte, en las capitales de provincia y en las cabeceras comarcales.

Como contrapunto a lo anterior, resulta interesante destacar que una buena parte de los municipios urbanos cuyo empleo ha sido hasta ahora menos castigado por la crisis tienen una economía de base agraria, aunque en algunos de ellos el turismo tiene también a veces una destacada presencia. Se pone así de manifiesto que estos dos sectores de actividad, agricultura y turismo, están contribuyendo a sostener algunos empleos en Andalucía. Ahora bien, como es conocido, estos sectores se caracterizan precisamente por aglutinar unas actividades en buena parte determinadas por su estacionalidad y que requieren una menor cualificación de los trabajadores, lo que pone en evidencia la fragilidad del mercado laboral en la región.

Llegado este punto, puede constatarse que, existen significativas diferencias entre las formas en que la crisis está afectando a los municipios urbanos ya que, mientras unos se encuentran en una situación verdaderamente crítica, otros parecen estar resistiéndola algo mejor; resulta interesante que entre estos últimos, como se señaló anteriormente, se incluyan las tradicionalmente conocidas como agro-ciudades.

Pese a lo apuntado, hay que tener en cuenta que el análisis de la incidencia de la crisis en el comportamiento del empleo de los municipios urbanos andaluces realizado hasta ahora no es más que una primera aproximación que deberá ser completada con trabajos posteriores. No hay que olvidar que profundizar en esta temática exige considerar no sólo la evolución del número de afiliaciones a la Seguridad Social, sino también a qué grupos de población concierne, en qué sectores de actividad se insertan, cuántos nuevos contratos se están firmando y de qué tipos, cómo evoluciona el número de parados y a qué grupos sociales les afecta. Sólo así será posible concluir si la crisis puede estar modificando y en qué medida al modelo socioeconómico que hasta ahora ha caracterizado a Andalucía. 
Igualmente, resulta de interés profundizar en el conocimiento de las diferentes formas en que está afectando la crisis a los distintos municipios lo que, como ya se ha comentado, está estrechamente relacionado no sólo con sus características socio-económicas (estructuras económicas heredadas, actividades predominantes, grado de especialización o de diversificación productiva, capacidad de generar empleo...), sino también territoriales (ámbito en el que se localizan, recursos naturales e infraestructurales con que cuentan, formas de ordenación del espacio...) y socio-institucionales (actitud más o menos proactiva de sus agentes públicos y privados, formas en que ponen en valor los recursos, capacidad para crear redes de colaboración...). Es evidente que para ello es necesario realizar estudios de caso, pues sólo así será posible proponer e implementar políticas públicas que, adaptándose a las condiciones y recursos de cada ámbito, puedan contribuir a enfrentar la crisis con efectividad y lograr superarla con modelos de desarrollo no sólo económicamente competitivos sino, sobre todo, ambientalmente respetuosos, y socialmente equitativos y solidarios.

\section{BIBLIOGRAFÍA}

ALBERTOS PUEBLA, J.M. y SÁNCHEZ HERNÁNDEZ, J.L. (Coords.) (2014): Geografía de la crisis económica en España, Valencia, Publicaciones de la Universidad de Valencia.

ÁlVAREZ PERALTA, I., LUENGO ESCALONILLA, F. y UXÓ GONZÁLEZ, J. (2013): Fracturas y crisis en Europa, Buenos Aires-Madrid, Eudeba y Clave Intelectual.

ARRIGHI, G. (1983): «Una crisis de hegemonía» en Amin-Arrigui-Gunder Frank-Wallerstein Dinámica de la crisis global, México, S. XXI, pp. 61-118.

ASKENAZY, P. y MÉHAUT, P. (2012): «Dotar de un nuevo porvenir al trabajo» en Los economistas aterrados, Cambiar de economía, Madrid, Catarata, pp. 190-204.

AURIOLES, J. (1995): «Retos e incertidumbres económicas en la Andalucía de los 90» en Ocho análisis de la Economía Andaluza, Sevilla, Instituto de Desarrollo Regional, pp. 7-39.

AYALA, L., MARTÍNEZ, R. y RUIZ HUERTA, L. (2013): «Desigualdad y redistribución en los países de la OCDE» en Primer Informe sobre la Desigualdad en España, Madrid, Fundación Alternativas, pp. 26-72.

BOCCARA, F., LE HÉRON, E. y PLIHON, D. (2012): «Por un sistema financiero emancipado de los mercados financieros» en Los economistas aterrados, Cambiar de economía, Madrid, Catarata, pp. 230-250.

BURRIEL, E. (2014): «El estallido de la burbuja inmobiliaria y sus efectos en el territorio» en Albertos Puebla, J.M. y Sánchez Hernández, J.L. (Coords.) (2014): Geografía de la crisis económica en España, Valencia, Publicaciones de la Universidad de Valencia, pp. 101-140.

CARAVACA, I. (1990): «Crisis, industria y territorio», Eria, n 21, pp. 9-21.

CARAVACA, I., GONZÁLEZ, G., MENDOZA, A. y SILVA, R. (2009): Dinamismo, innovación y desarrollo en ciudades pequeñas y medias de Andalucía, Sevilla, Consejo Económico y Social de Andalucía (Premio de Investigación 2008).

CARAVACA, I, GONZÁLEZ-ROMERO, G. y LÓPEZ, P. (2014): «Crisis y desarrollo territorial en las ciudades de Andalucía». Revista de Estudios Regionales, $\mathrm{n}^{\circ}$ 100, pp. 17-45.

CASTELLS, M. y HALL, P. (Eds.) (1991): Andalucía: Innovación tecnológica y desarrollo económico, Madrid, Espasa Calpe, 2 vol. 
CHRISTOPHERSON, S., MICHIE, J. y TYLER, P. (2010): «Regional resilience: theoretical and empirical perspectives» Cambridge Journal of Regions, Economy and Society, $\mathrm{n}^{\circ} 3$. pp. 3-10.

CORPATAUX, J., CREVOISIER, O. y THEURILLAT, T. (2009): «The expansion of the finance industry and its impact on the economy: a territorial approach base on Swiss pension funds», Economic Geography, no 85 (3), pp. 3313-334.

DAHER, A. (2013): «El sector inmobiliario y las crisis económicas» EURE. Revista Latinoamericana de Estudios Urbano-Regionales, vol. 39, $\mathrm{n}^{\circ}$ 118, pp. 47-76.

DELGADO CABEZA, M. (1981): Dependencia y Marginación de la Economía Andaluza, Córdoba, Publicaciones del Monte de Piedad y Caja de Ahorros de Córdoba.

DELGADO CABEZA, M. (2002):Andalucía en la Otra Cara de la Globalización. Ed. 1. Sevilla, Mergablum Edición y Comunicación. DELGADO CABEZA, M. (2006): «Economía, Territorio y Desigualdades Regionales» en Revista de Estudios Regionales $\mathrm{n}^{\mathrm{o}} 75$, pp. 93-128.

EKAIZER, E. (2012): Indecentes, Madrid, Espasa.

FERNÁNDEZ DURÁN, R. (2006): El tsunami urbanizador español y mundial[En línea] http://www.ecologistasenaccion.org/article.php3?id_article=4824[6 de junio de 2010]

FERNÁNDEZ DURÁN, R. (2011): La quiebra del capitalismo global: 2000-2030. Bilbao, Virus Editorial.

FERNÁNDEZ TABALES, A. (2012): El sector de la construcción en Andalucía. Sevilla, Universidad de Sevilla y Agencia IDEA.

FERNANDEZ TABALES, A. y CRUZ, E. (2014): «El sector de la construcción en Andalucía en el contexto de la crisis: colapso de un modelo y efectos territoriales». En Albertos, J.M- Sánchez, J.L. (Coords.) Geografía de la crisis económica en España. Valencia: Publicacions de la Universitat de València, pp. 435-466.

GARCÍA BELLIDO, J. (2005): «Por una liberalización del paradigma urbanístico español: el tsunami urbanístico que arrasará el territorio» Ciudad y Territorio-Estudios Territoriales, XXXVII, nº 144, pp.273-288.

GARCÍA GARCÍA, A. (2012): El dinamismo socioeconómico de Andalucía. Territorios ganadores y territorios emergentes. Sevilla: Universidad de Sevilla y Agencia IDEA.

GEORGE, S. (2010): Sus crisis, nuestras soluciones. Barcelona Icaria-Intermón-Oxfam.

HARVEY, D. (2012): El enigma del capital y las crisis del capitalismo. Madrid, Akal.

LÓPEZ, I. y RODRÍGUEZ, E. (2010): Fin de ciclo. Financiarización, territorio y sociedad de propietarios en la onda larga del capitalismo hispano (1959-2010), Madrid, Traficantes de Sueños.

MARTIN, R. (2012): «Regional economic resilience, hysteresis and recessionary shocks» Journal of Economic Geography, vol.12, pp.1-32.

MAYOR ZARAGOZA, F. (2011): «Traspasar los límites de lo posible», VVAA,

Reacciona, Madrid, Aguilar.

MÉNDEZ, R. (2012): «Ciudades, crisis y desempleo en España», Revista de Estudios de la Fundación $1^{\circ}$ de Mayo, ${ }^{\circ}$ 43, pp. 13-15.

MÉNDEZ, R. (2013 a): Las escalas de la crisis. Ciudades y desempleo en España, [En línea] Fundación $1^{\circ}$ de Mayo, Colección Estudios www.1mayo.cooo.es. [30 de noviembre de 2013] 
MÉNDEZ, R. (2013 b): «Crisis económica y reconfiguraciones territoriales» en Llusa-Feliu, R. y Paunero, X. (Eds.) Crisis económica e impactos territoriales, V Jornadas de Geografía Económica, Girona, 2012, Grupo Geografía Económica (AGE) y Departamento de Geografía de la Universidad de Girona, pp. 36-73.

MÉNDEZ, R. (2013): «Crisis económica, vulnerabilidad urbana y desempleo en España» Ciudad y Territorio Estudios Territoriales, XLV (178), pp1-19.

MÉNDEZ, R. (Dir.) (2007): Dinámica de las ciudades de Andalucía, Sevilla, Instituto de Estadística de Andalucía.

MÉNDEZ, R., ABAD, L. y CARAVACA, I. - GONZÁLEZ, G. (2010): «Las ciudades de Andalucía ante la sociedad del conocimiento» Scripta Nova [En línea],vol XIV, nº 345 http://www.ub.es/geocrit/sn/sn-345htm [12 de diciembre de 2013]

NAREDO, J.M. (2010). «El modelo inmobiliario español y sus consecuencias». Coloquio Urbanismo, Democracia y Mercado: una experiencia española (1970-2010). ETS Arquitectura y Casa de Velázquez, Madrid.

MORIN, E. (2011): La Vía. Para el futuro de la humanidad, Barcelona, Paidós Estado y Sociedad.

OBSERVATORIO METROPOLITANO (2011): La crisis que viene. Algunas notas para afrontar esta década, Madrid, Traficantes de sueños.

ORHANGAZI, O. (2008): «Financialization and Capital Accumulation in the Nonfinancial Corporate Sector: A Theoretical and Empirical Investigation on the US Economy, 19732003» Cambridge Journal of Economics, 32(6), pp. 863-886.

OXFAM INTERMÓN (2013): La trampa de la austeridad. El verdadero coste de la desigualdad en Europa, [En línea]

http://www.oxfamintermon.org/es/informate/publicaciones/estudios [22 de octubre de 2013].

OXFAM INTERMÓN (2014): Gobernar para las élites. Secuestro democrático y desigualdad económica: Reflexiones sobre España, [En línea]

http://www.oxfamintermon.org/es/documentos/17/01/14/gobernar-para-elites-secuestrodemocratico-desigualdad-economica [20 de enero de 2014].

PITA, M.F. y PEDREGAL, B. (Coords.) (2011): Tercer Informe de Desarrollo Territorial de Andalucía 2010, Sevilla, Universidad de Sevilla, Agencia de Innovación y Desarrollo de Andalucía, Grupo de Investigación Estructuras y Sistemas Territoriales.

ROCHA, F.- ARAGÓN, J. (2012): «La crisis económica y sus efectos sobre el empleo» Colección Infoemes, $\mathrm{n}^{\circ}$ 55, Fundación $1^{\circ}$ de Mayo.

ROMERO, J. y COLLADO, J.C.-RODRÍGUEZ, M.T. (2014): «La economía política de la desigualdad. Los recortes en el sector público y sus repercusiones para el Estado de Bienestar en España» en Albertos Puebla, J.M.-Sánchez Hernández, J.L. Coords. (2014): Geografía de la crisis económica en España, Valencia, Publicaciones de la Universidad de Valencia, pp. 329-376.

SÁNCHEZ HERNÁNDEZ, J.L. (2013): «Sensibilidad y resiliencia de las regiones españolas durante las crisis económicas (1976-2011)» en Llusa-Feliu-Paunero. Edits, Crisis económica e impactos territoriales, V Jornadas de Geografía Económica, Girona, 2012, Grupo Geografía Económica (AGE) y Departamento de Geografía de la Universidad de Girona, pp. 74-96. 
STERDYNIAK, H. (2012): «¿Que política económica? Muertes y resurrecciones del keynesianismo» en Los economistas aterrados, Cambiar de economía, Madrid, Catarata, pp. 21-48.

TORRES LÓPEZ, J. (2011): Contra la crisis, otra economía y otro modo de vivir. Móstoles (Madrid), Ed. HOAC.

TOURAINE, (2011): Después de la crisis, Barcelona, Paidos.

VVAA (2012): Los economistas aterrados. Cambiar de economía, Madrid, Catarata.

ZOIDO, F. Coord. (2001): Informe de Desarrollo Territorial de Andalucía, Sevilla, Universidad de Sevilla, Fundación Sevillana de Electricidad, La General. Caja de Granada. (Premio de Economía y Hacienda, Junta de Andalucía).

ZOIDO, F. y CARAVACA, I. Coords. (2005): Andalucía. Segundo Informe de Desarrollo Territorial, Universidad de Sevilla, Agencia de Innovación y Desarrollo de Andalucía, Fundación Sevillana-Endesa. 